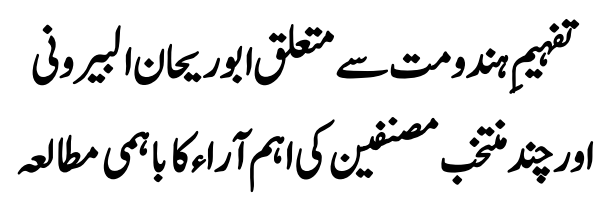

\title{
Understanding Hinduism, a Collective Study by Abu Raihan Al- Beruini and Others with their Related Important Views
}

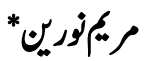

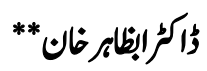

\begin{abstract}
Hinduism is one of the most ancient religions of the world originated in the Subcontinent. This religion has always been of a significant value in the history of world religions. The subcontinent has been the birth place of many Dharmic Religions like Buddhism and Jainism, as well as it has been a center of many Abrahamic Religions such as Christianity and Islam. The Interaction between the Muslims and the ancient people of subcontinent began right after the migration of Prophet Muhammad in Madinah. Therefore, the Muslim scholars tended to study the religion of Indian people and their life style. Abu Rehan Alberuni was the first person who initiated Indology, the "كتاب فى تحقيق ماللإند من study of indo religions. He wrote an encyclopedic book

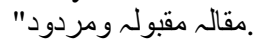

After Al-Beruni, the Hinduism became a subject of research for the muslim scholars. Many Muslim scholars like Maulana Ubaid Ullah, Dr. Meher Abdulhaq, Maulana Shams Naveed, Dr. Zakir Naik and Muhammad Shariq have profound academic works on Hinduism. Therefore, in this article the views of these thinkers and understanding of Hinduism will be reviewed.

Key Words: Dharmic religions, Subcontinent, Muslim Scholars, Hinduism.

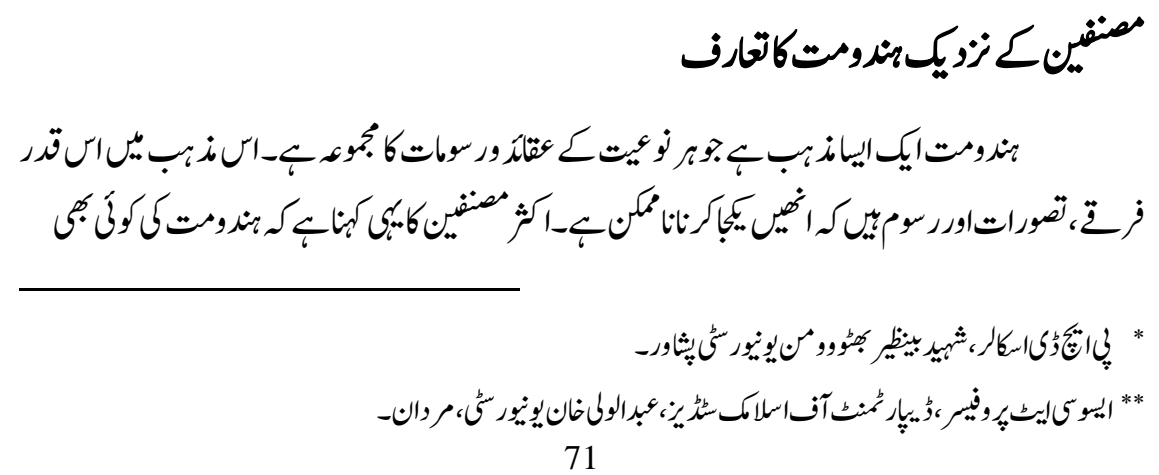




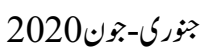

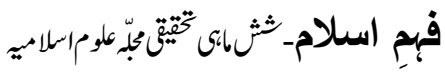

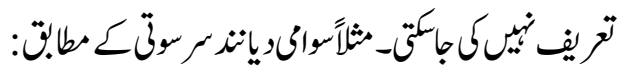

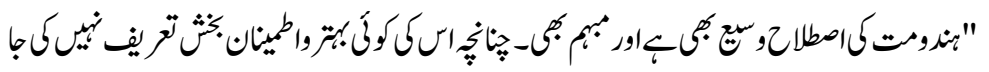

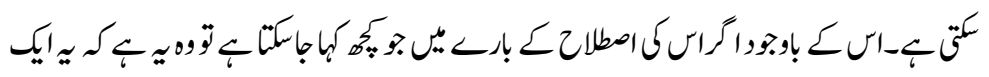

ن:

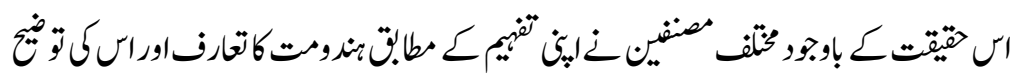

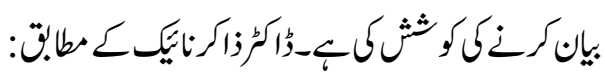

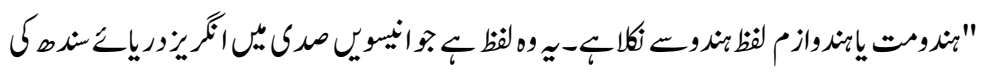

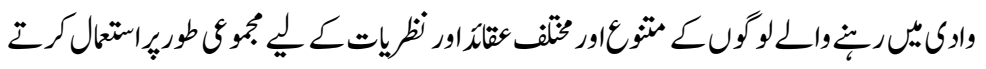

$2 "-\ddot{E}$

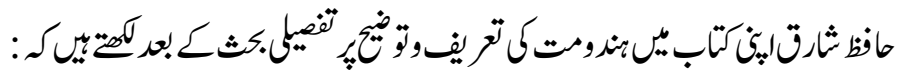

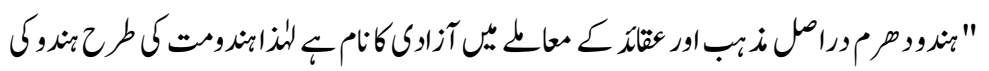

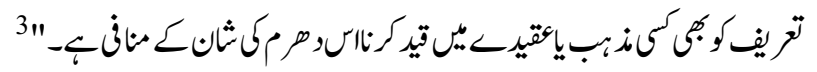

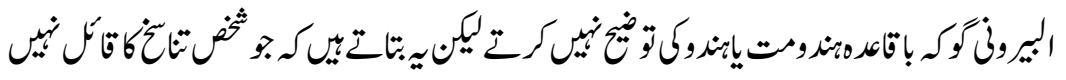

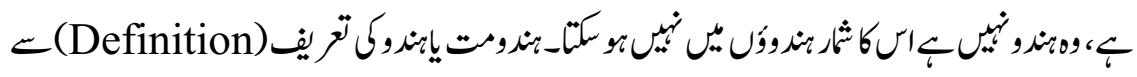

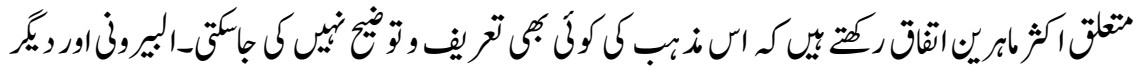

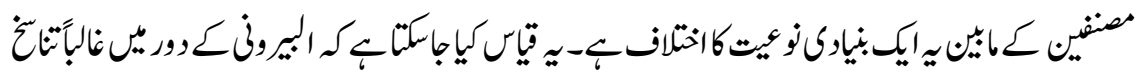

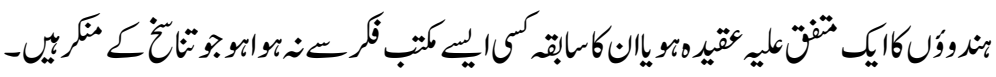

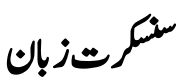

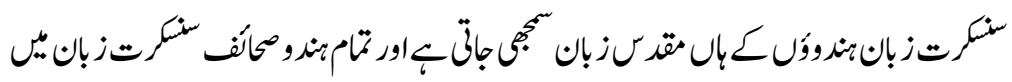

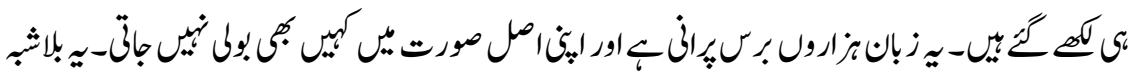

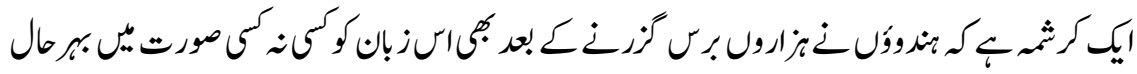

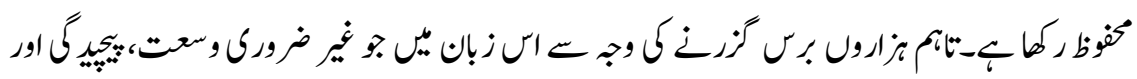

72 


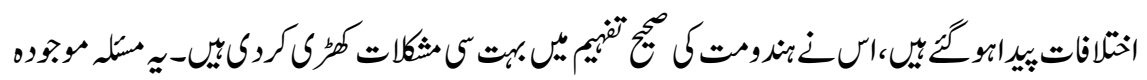

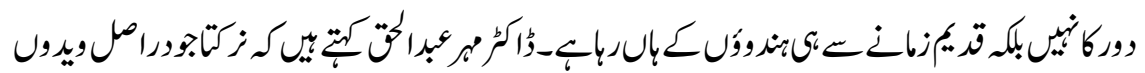

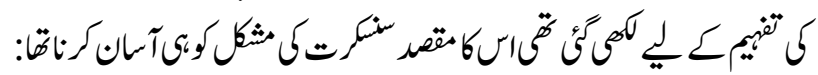

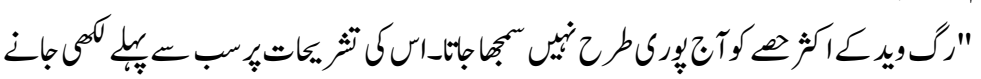

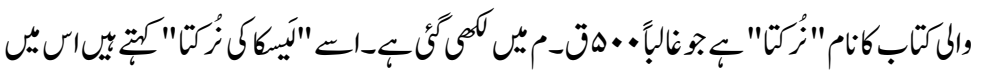

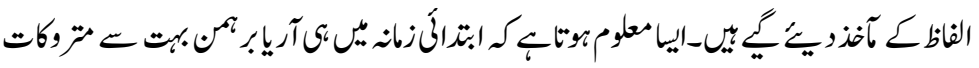

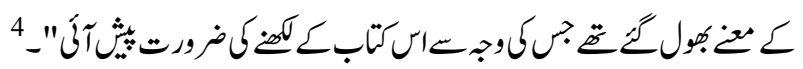

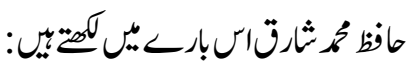

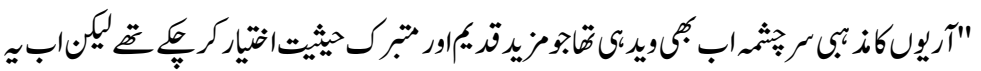

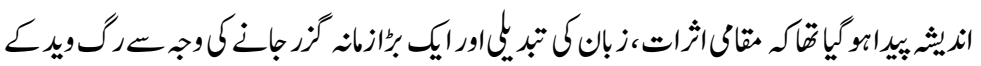

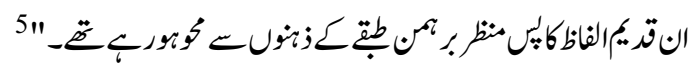

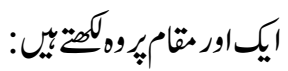

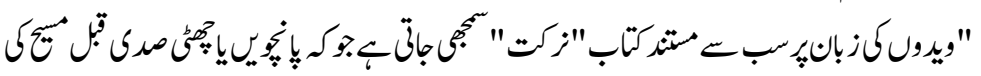

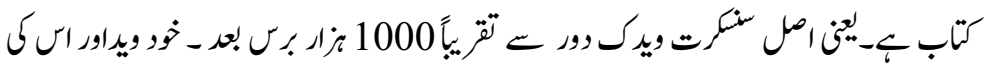

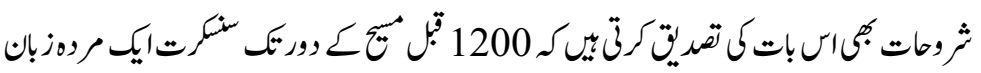

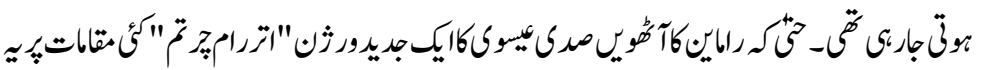

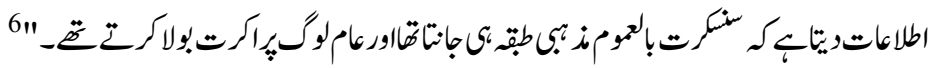

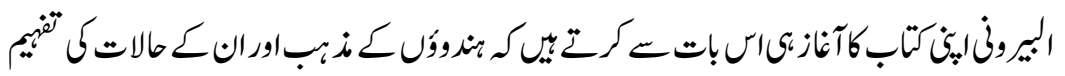

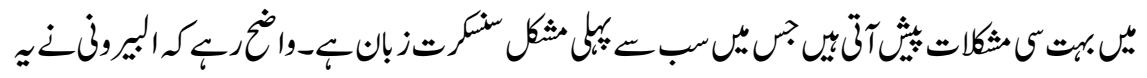

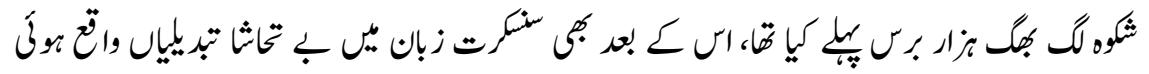

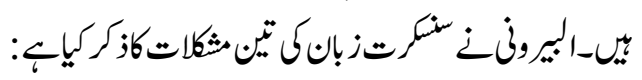

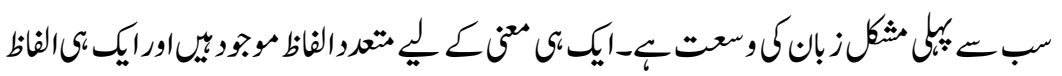

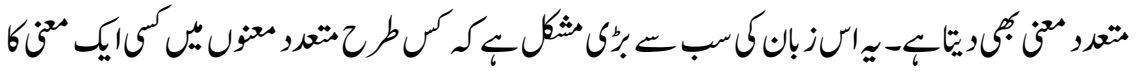

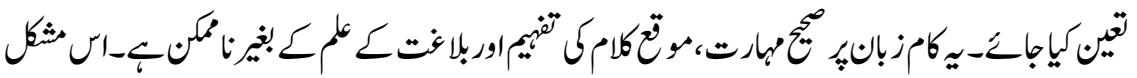

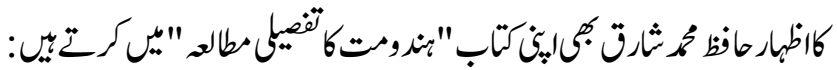




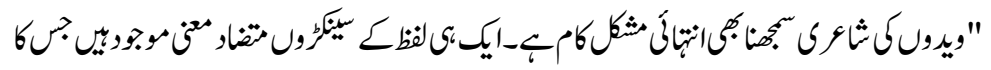

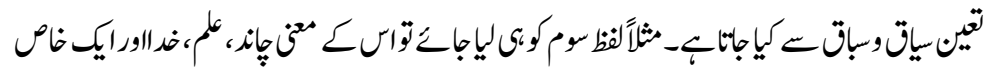

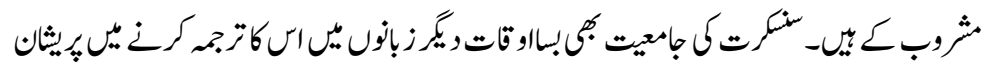

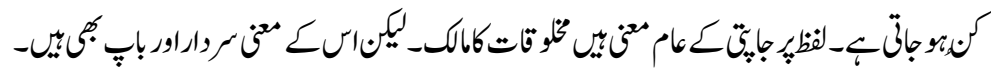

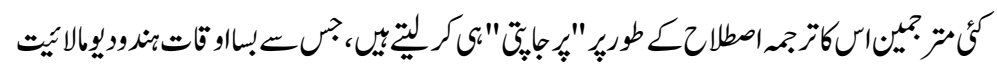

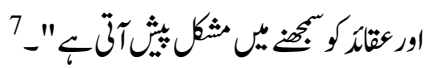

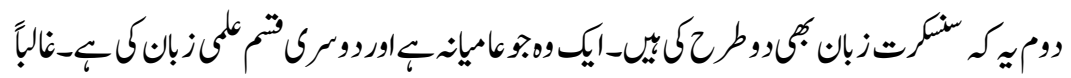

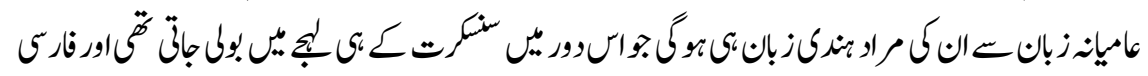

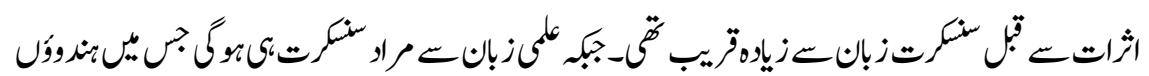

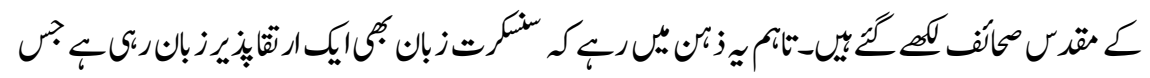

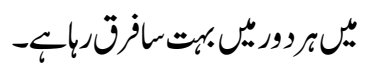

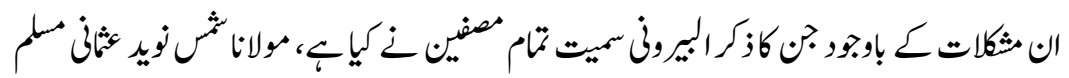

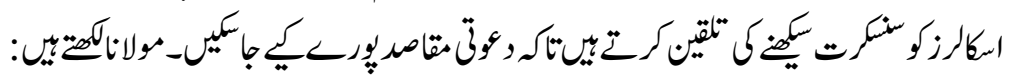

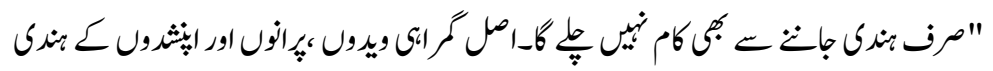

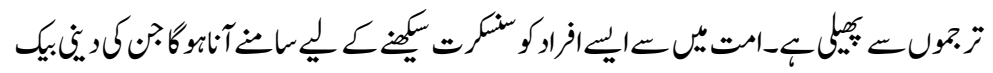

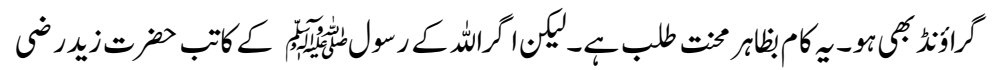

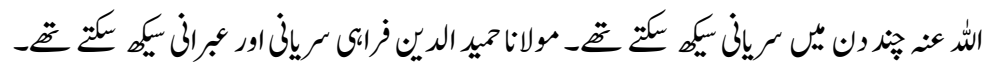

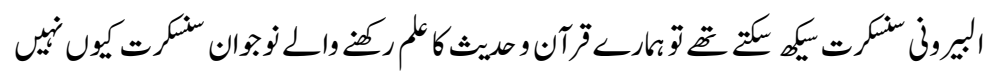

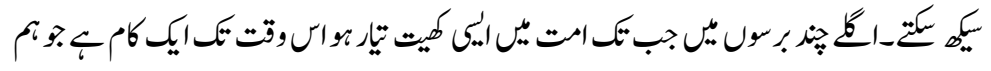

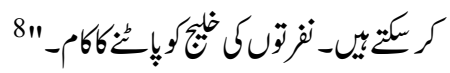

\section{ويركتنارف}

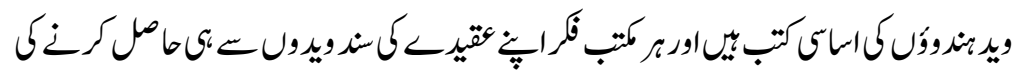

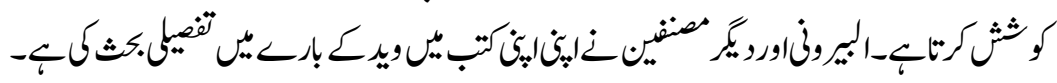

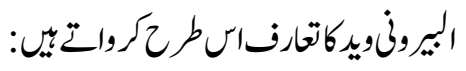




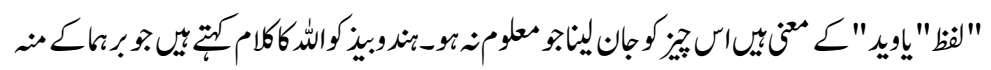

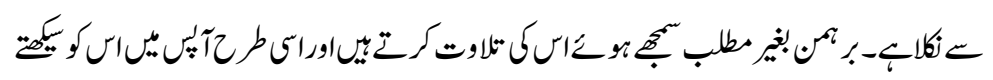

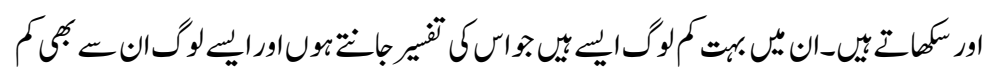

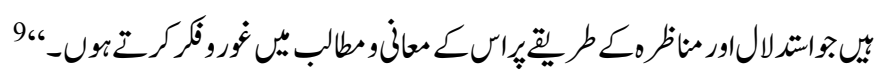

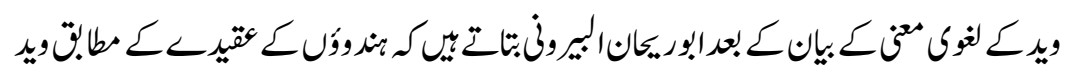

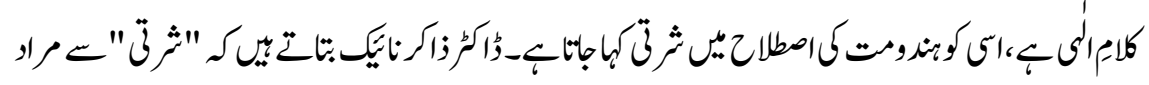

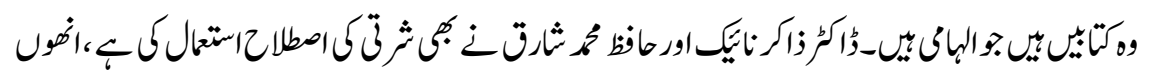

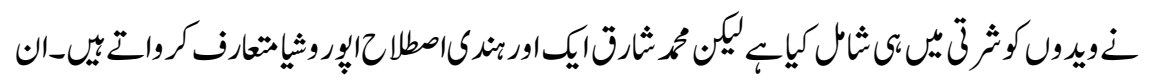

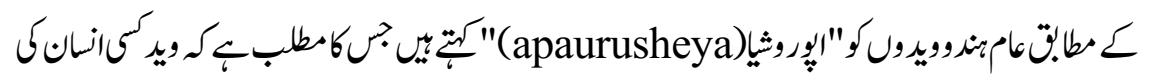

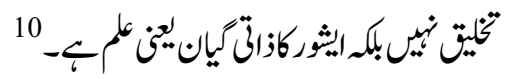
وراكمّزاكرنائكس ع مطانق:

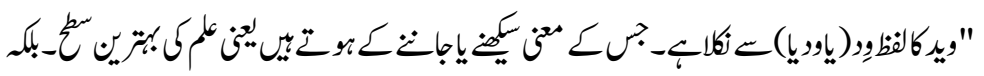

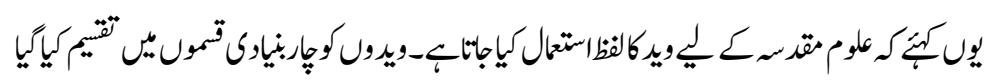
$11 "-4$

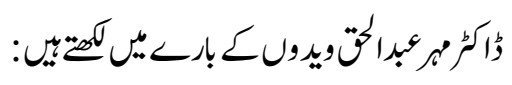

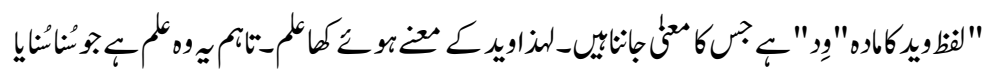

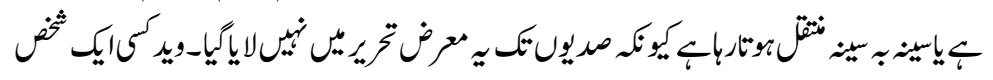

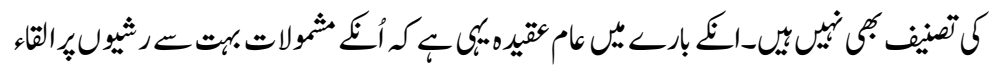

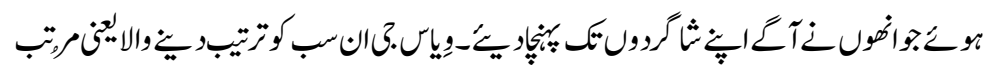
يالئير

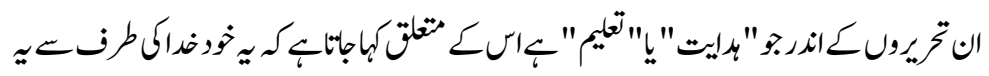

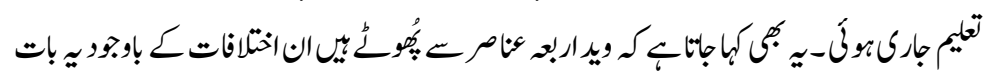

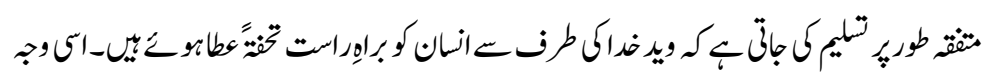

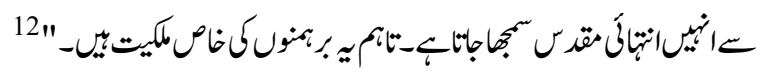




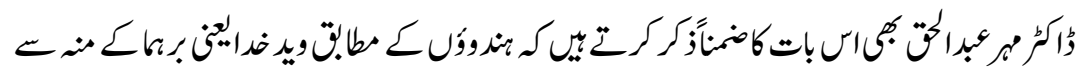

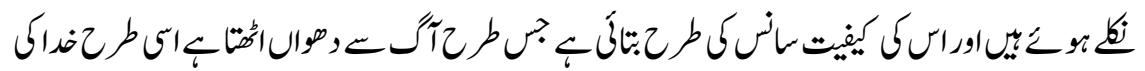

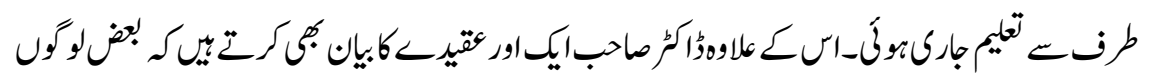

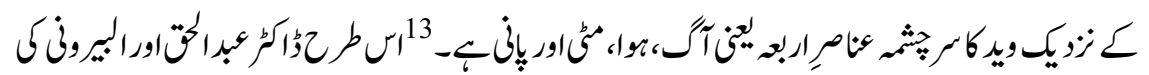

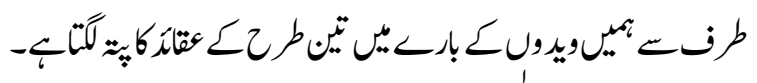

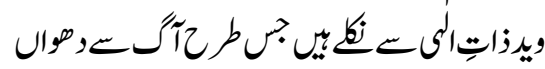

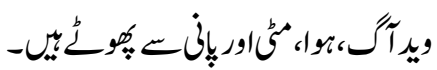

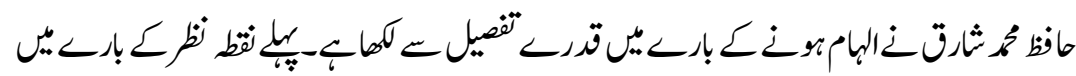

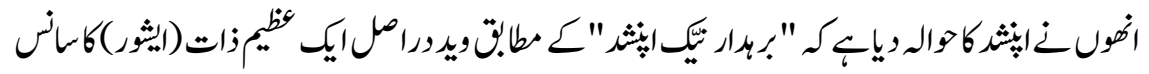

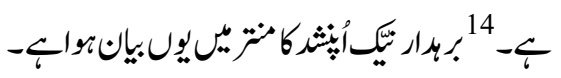

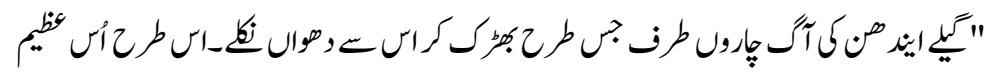

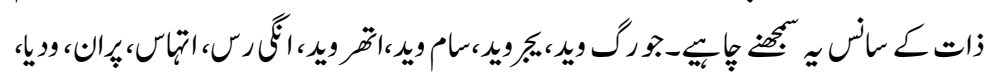

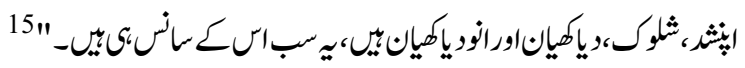

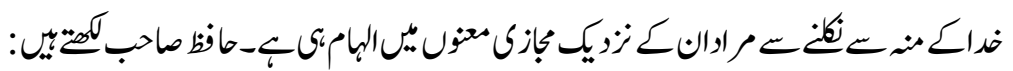

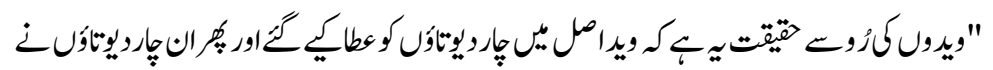

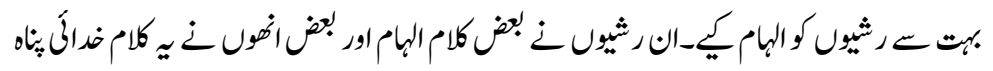
(Under-ispiration)

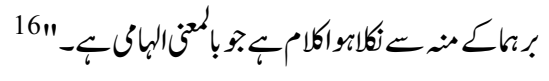

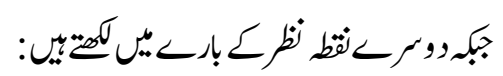

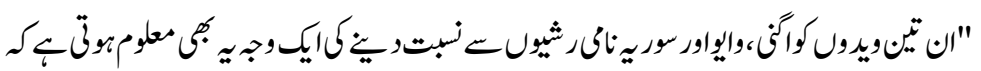

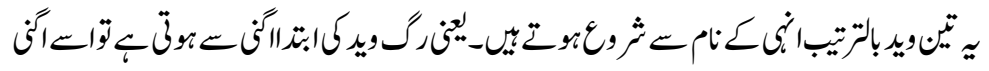

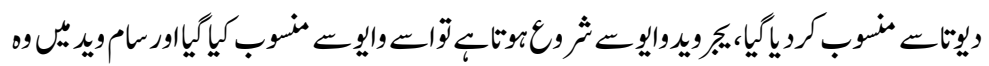

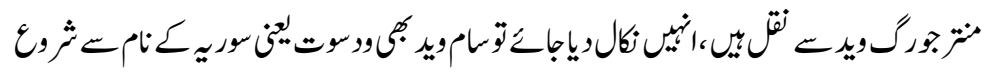
$17 "-6 \%$ 


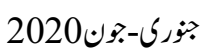

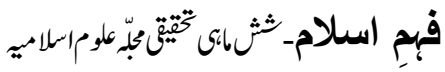

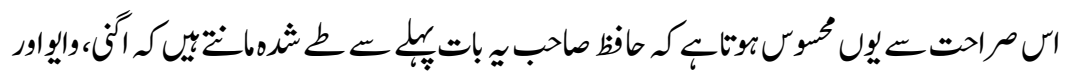

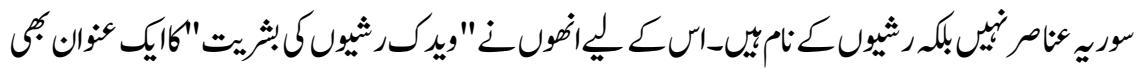

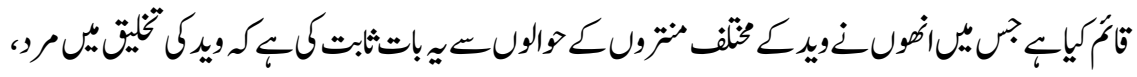

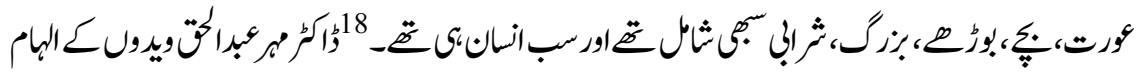

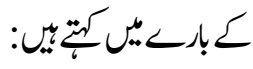

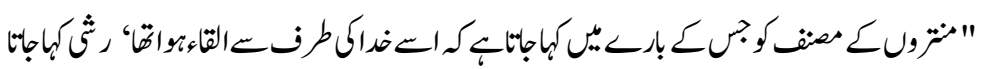

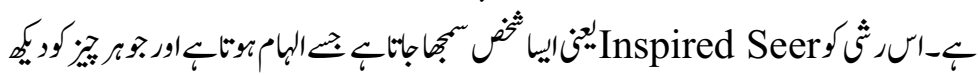
$19 "-4$

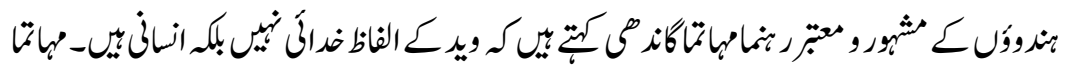

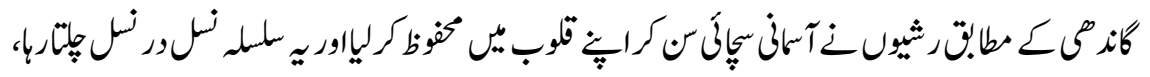

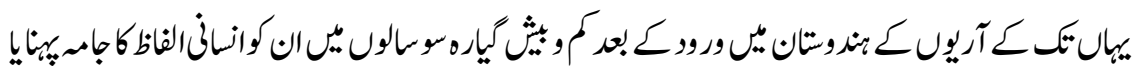

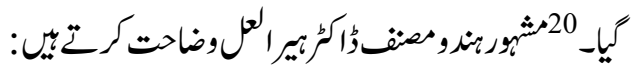

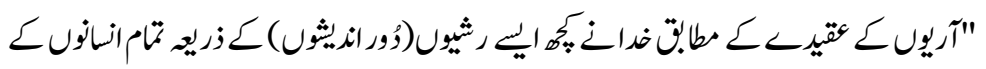

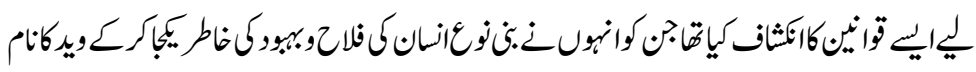

"21"-l

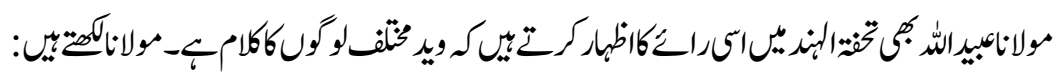

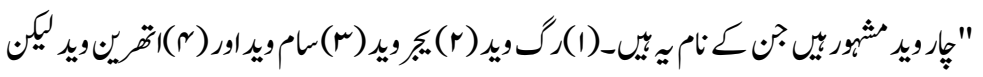

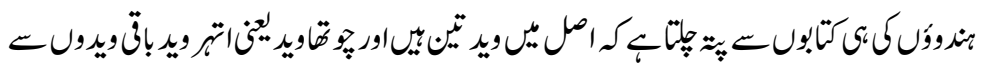

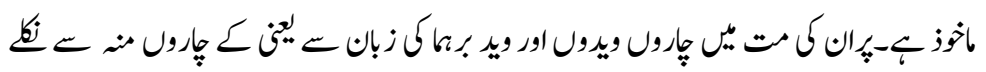

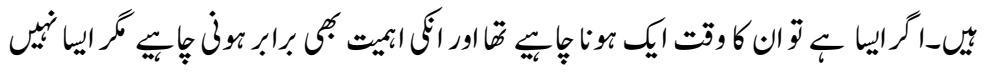

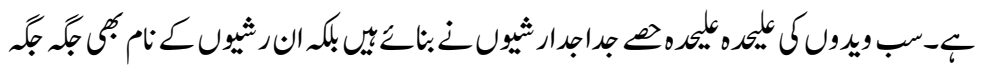

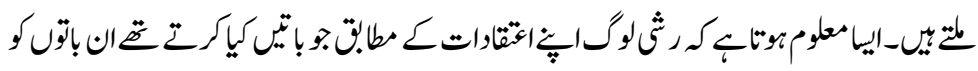

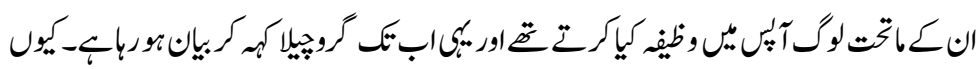

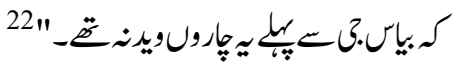

77 


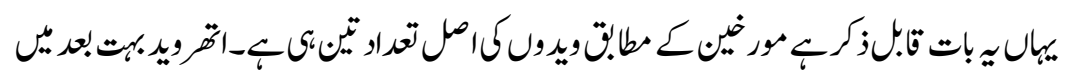

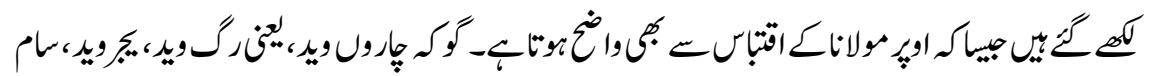

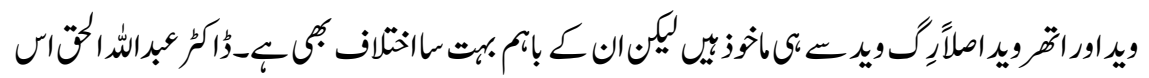

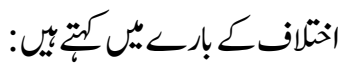

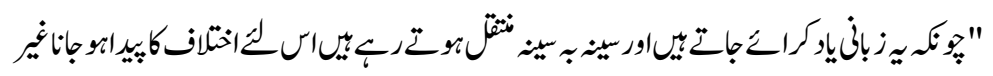

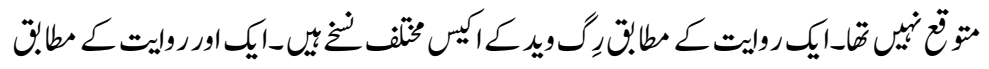

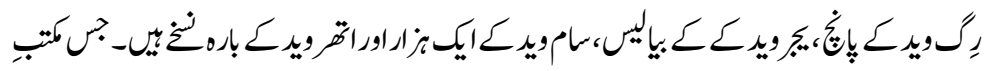

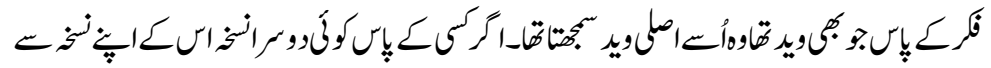

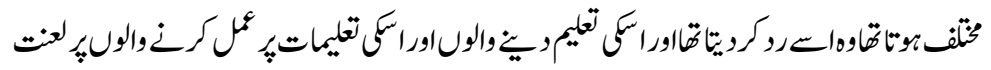

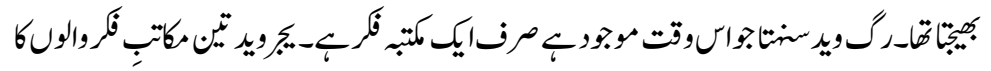

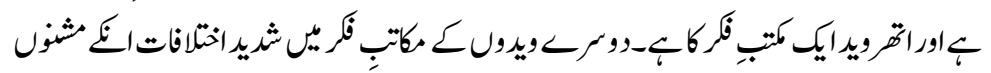

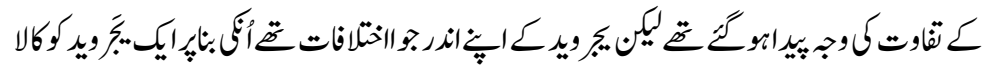

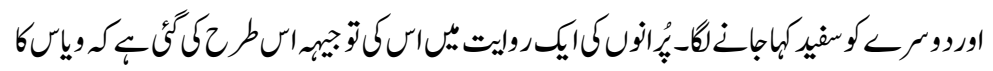

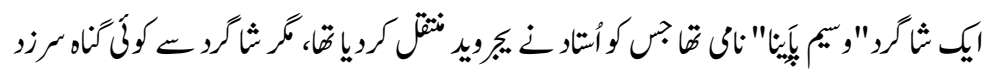

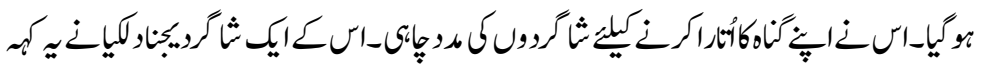

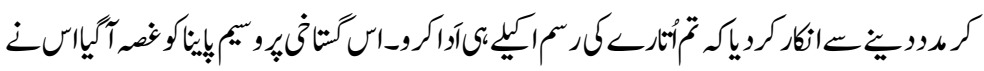

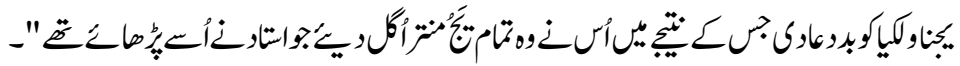

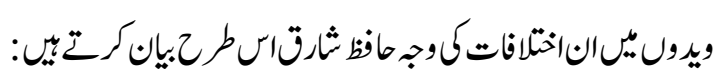

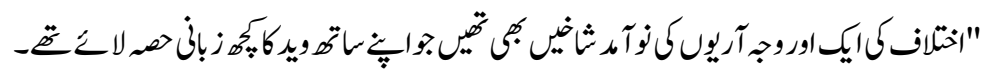

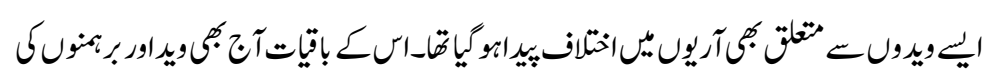

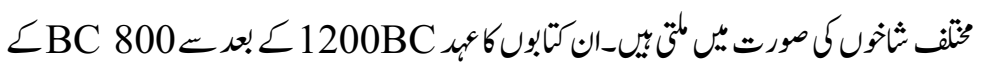

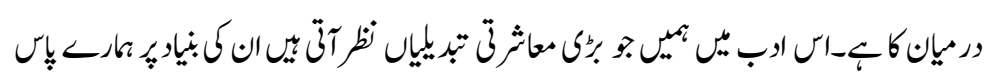

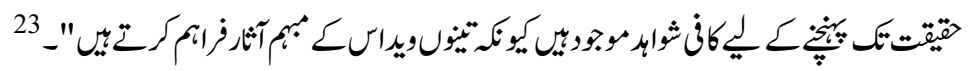

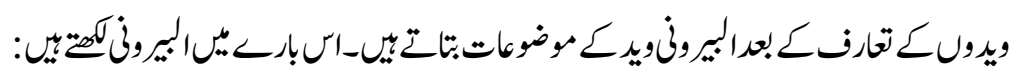




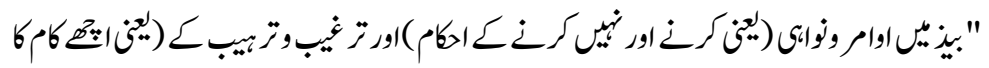

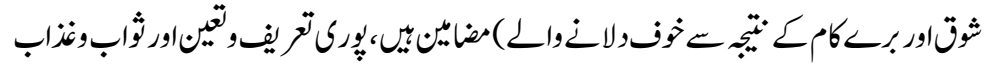

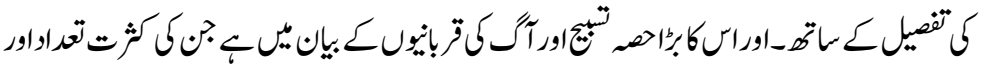

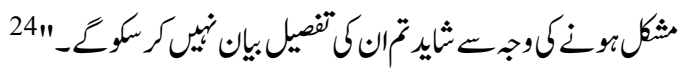

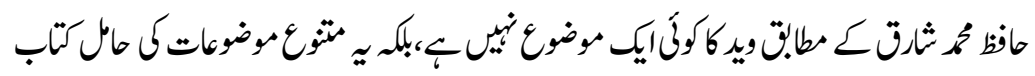

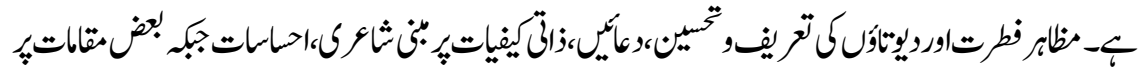

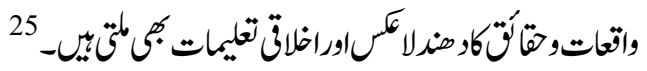

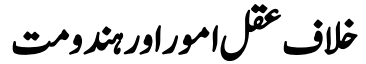

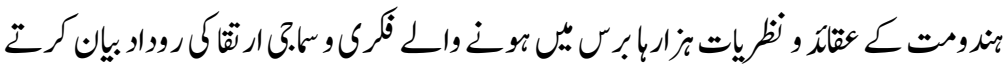

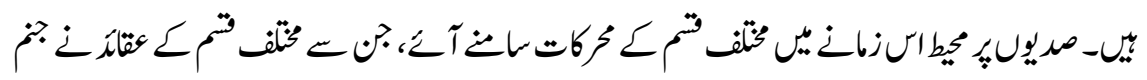

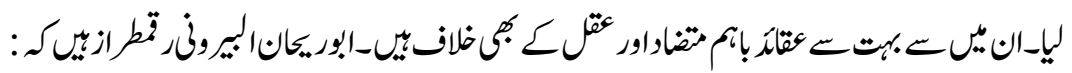

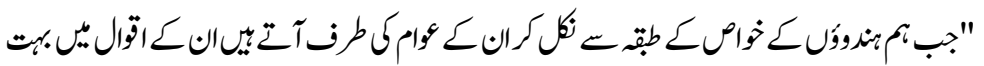

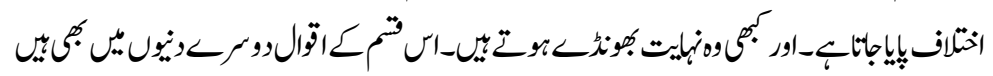

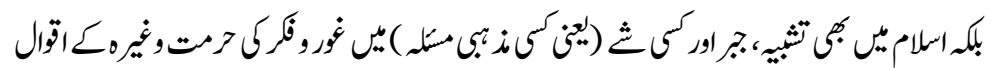

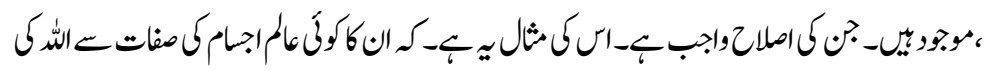

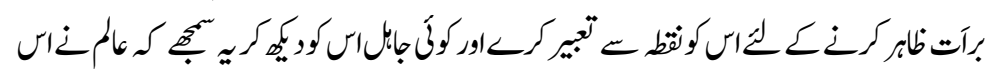

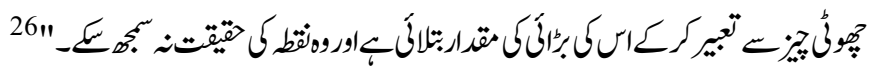

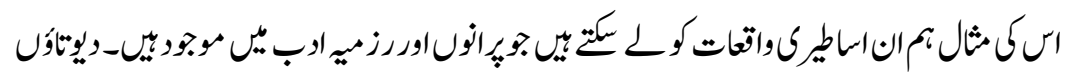

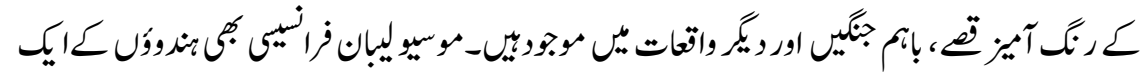

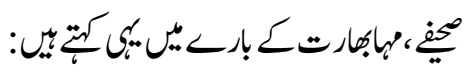

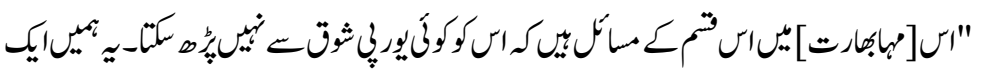

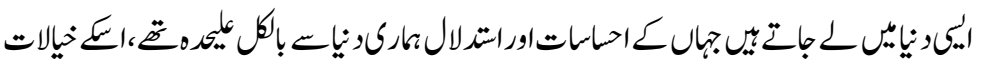




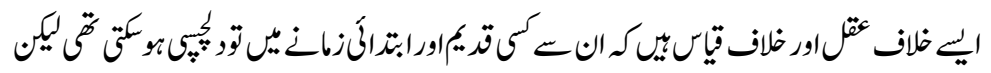

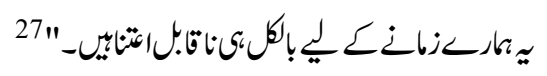

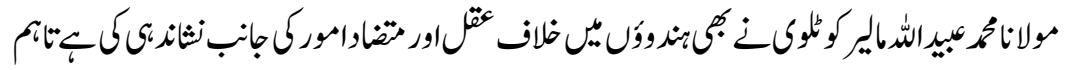

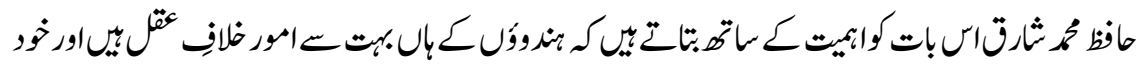

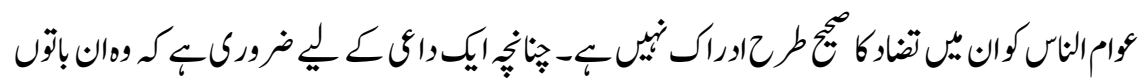

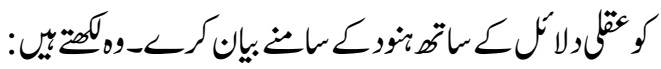

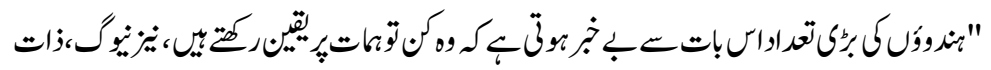

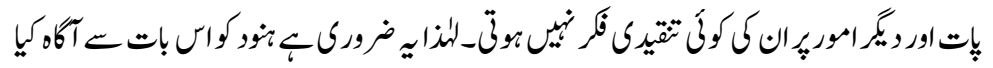

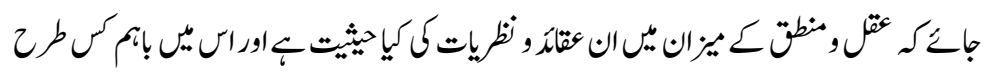
تضاوب-

\section{رسوموروان}

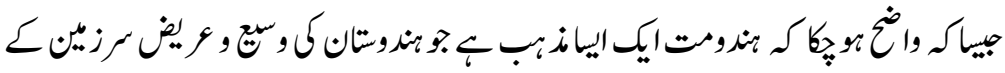

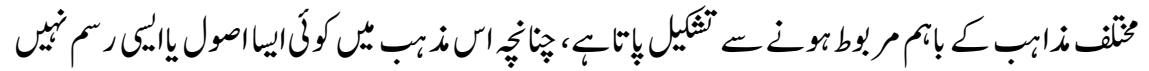

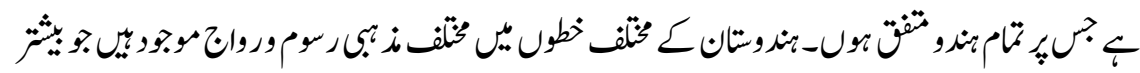

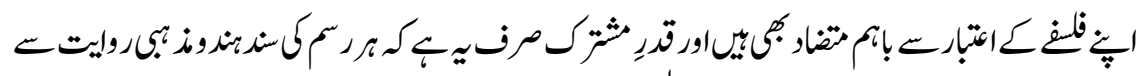

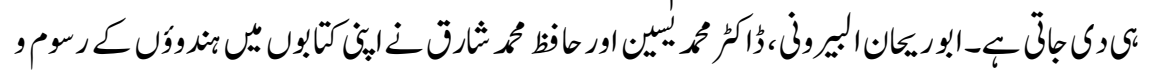

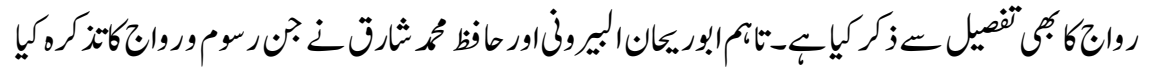

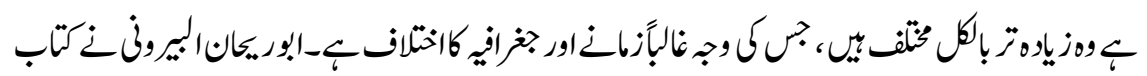

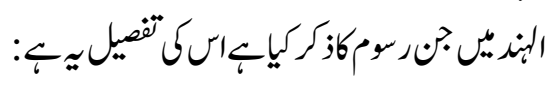

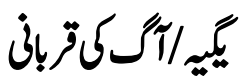

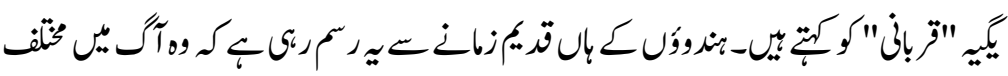

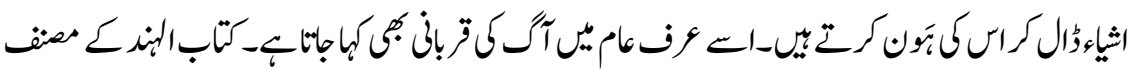

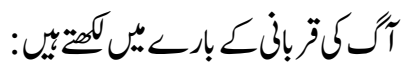




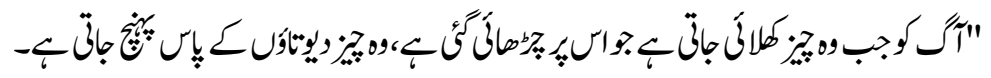

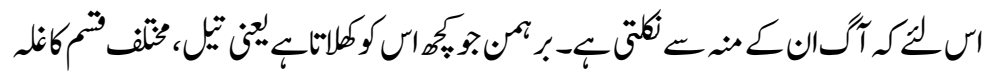

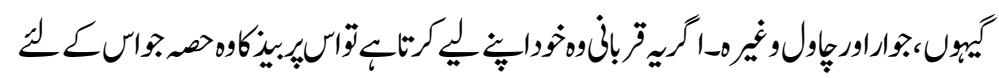

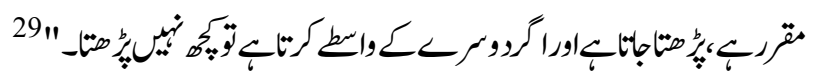

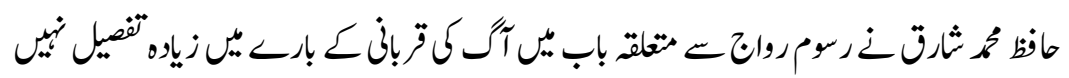

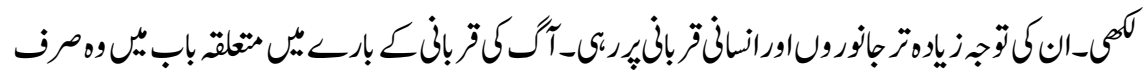

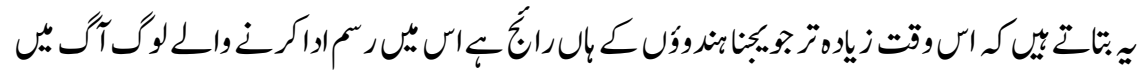

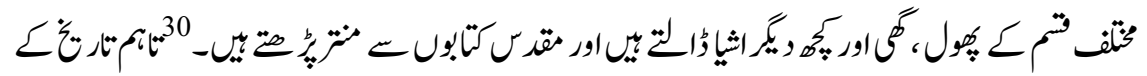

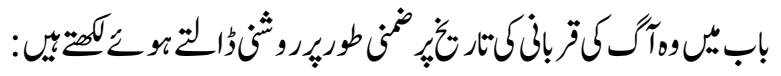

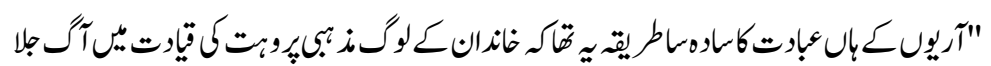

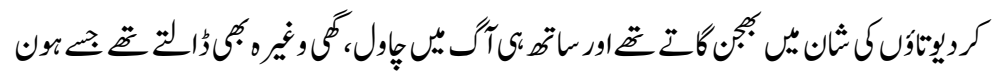

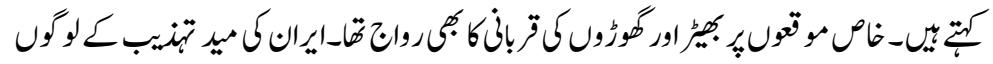

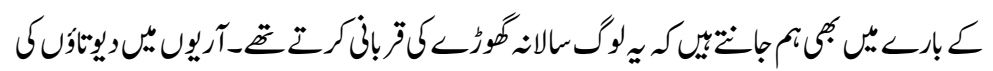

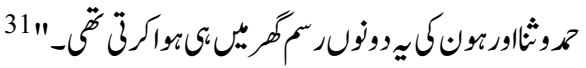

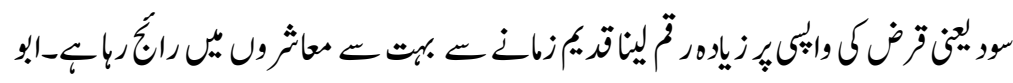

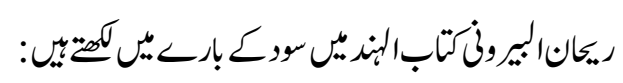

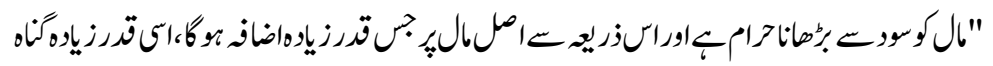

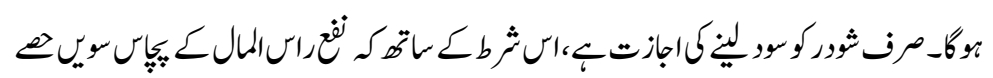

$$
32 " \text { "1/50) }
$$

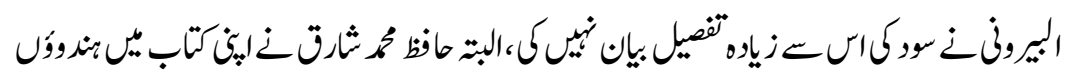

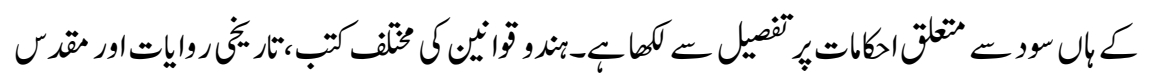

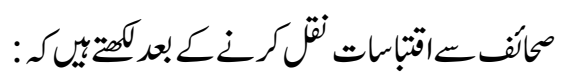




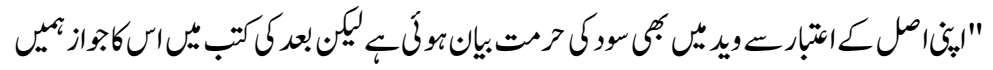

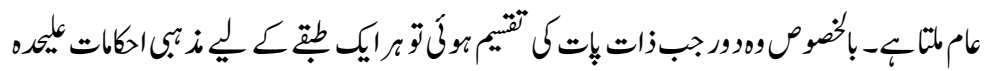

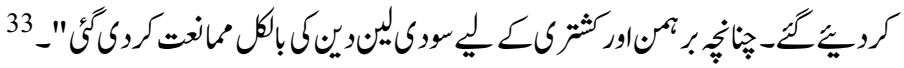

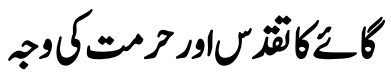

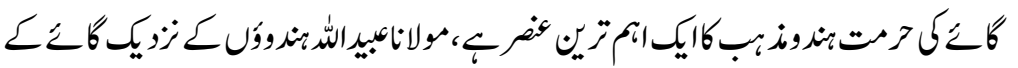

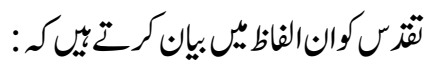

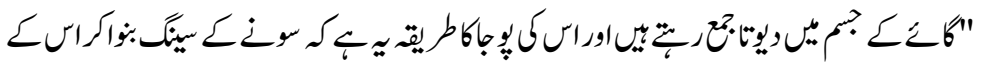

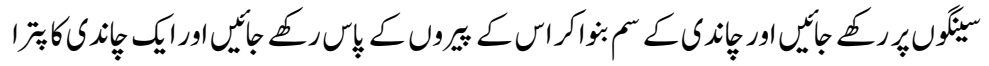

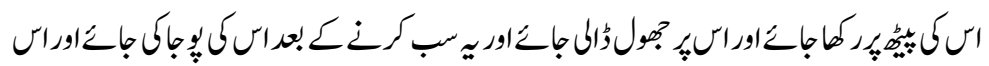

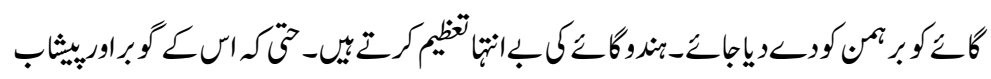

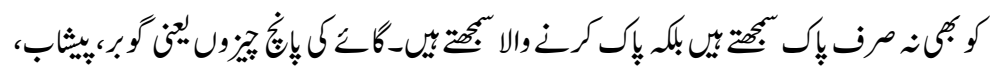

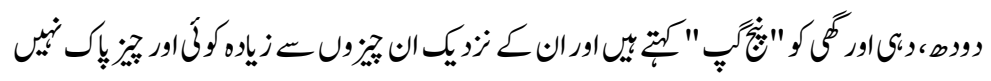

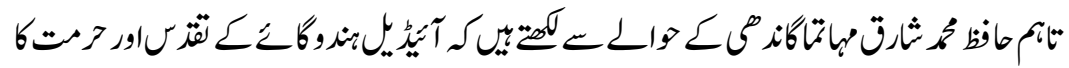

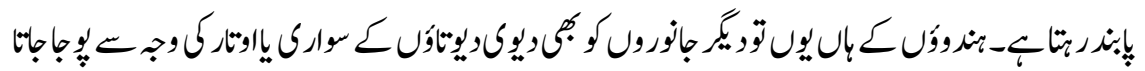

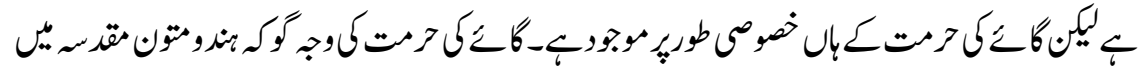

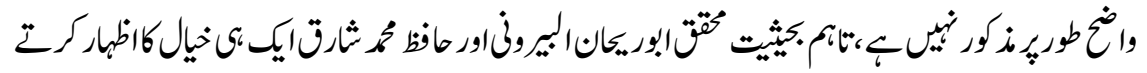

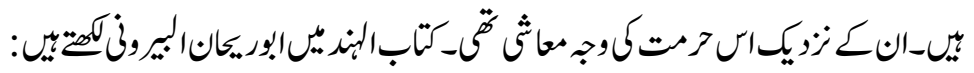

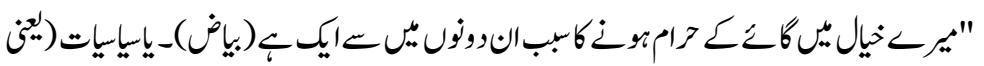

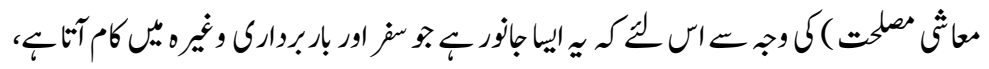

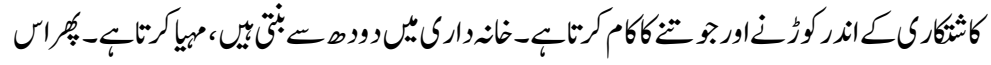

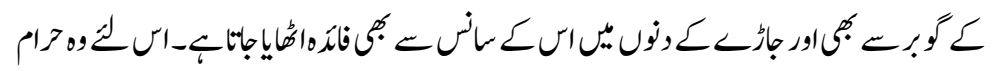




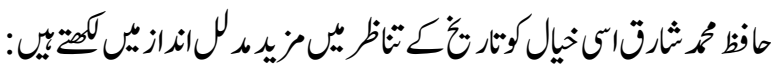

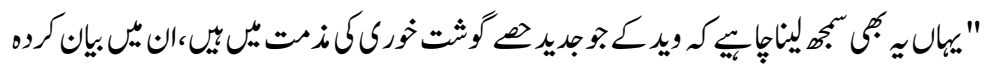

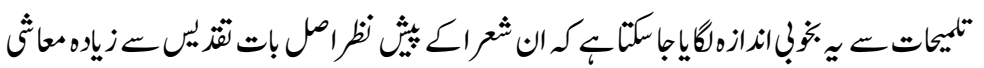

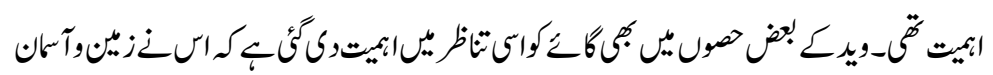

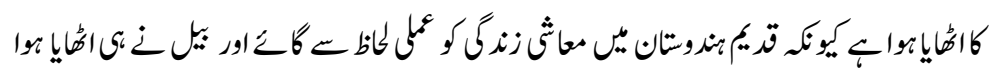

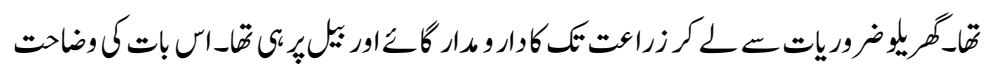

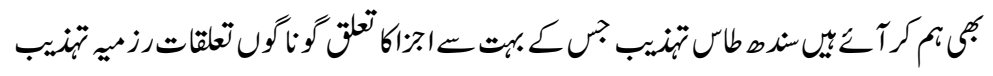

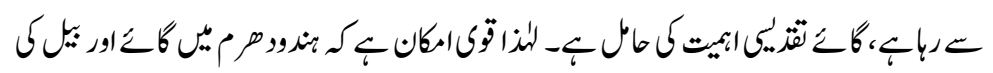

$$
\begin{aligned}
& \text { انميتاكسبب }
\end{aligned}
$$

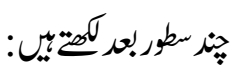

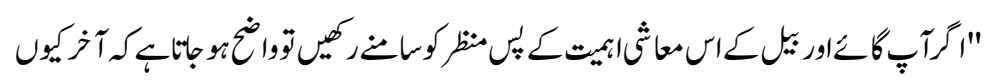

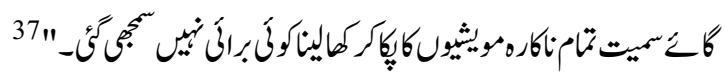

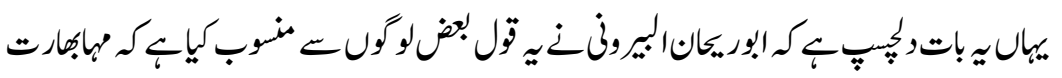

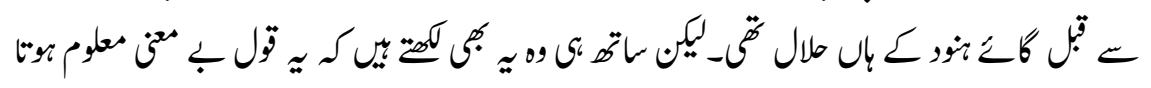

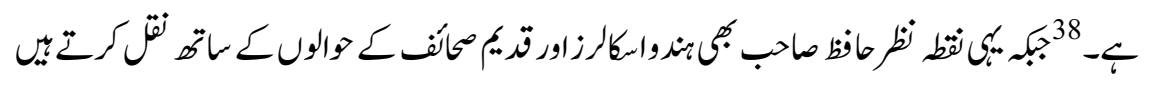

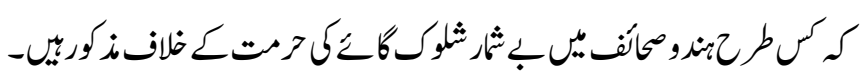

\section{ملاصم كلام}

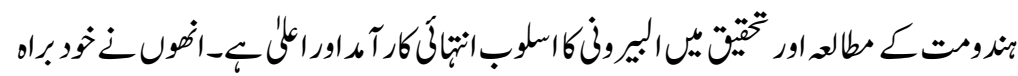

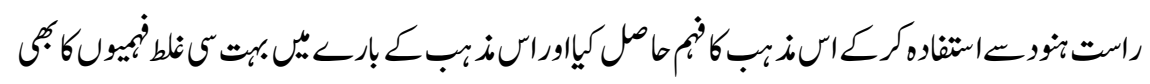

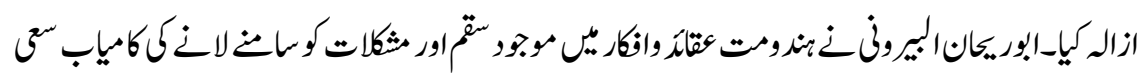

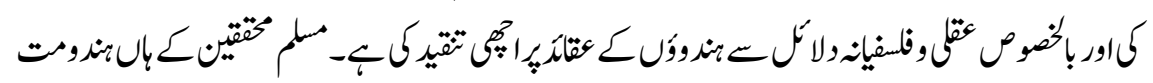

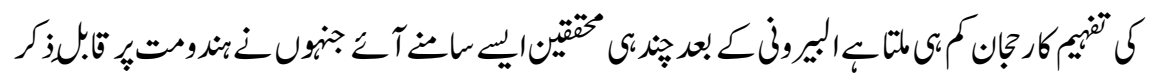




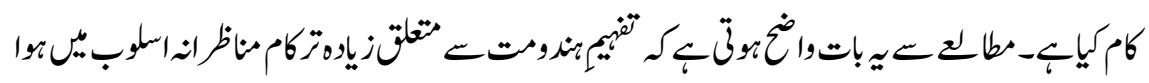

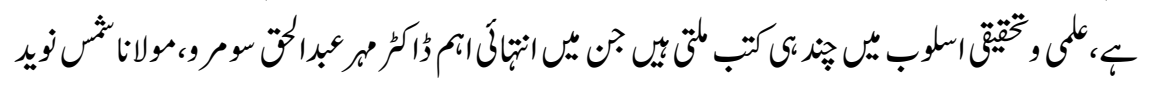

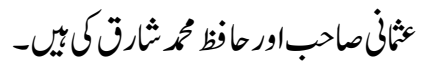

\section{حوالد جات}

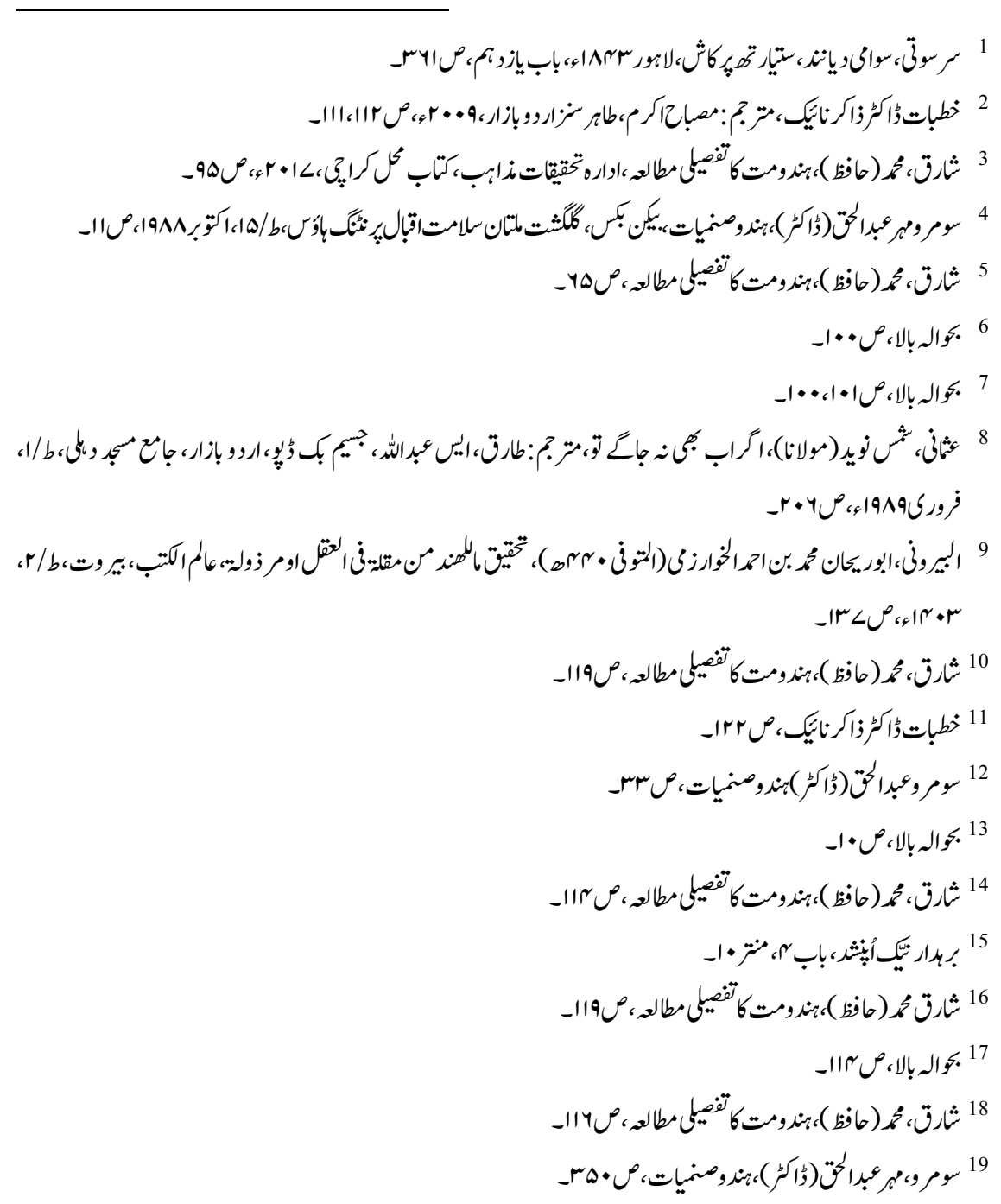




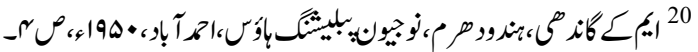

$$
\begin{aligned}
& 21
\end{aligned}
$$

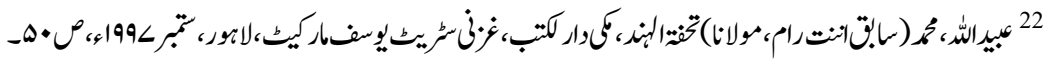

$$
\begin{aligned}
& 23
\end{aligned}
$$

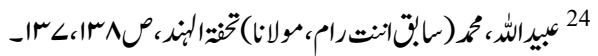

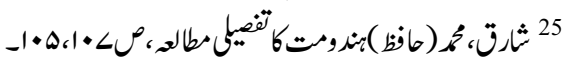

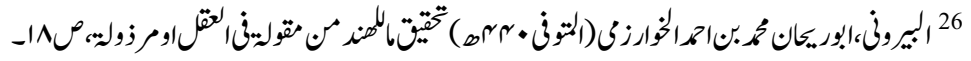

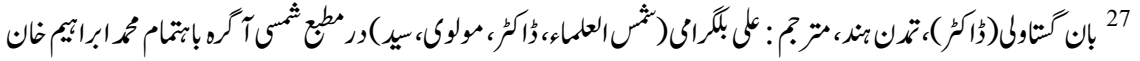

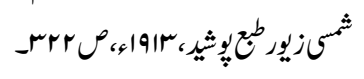

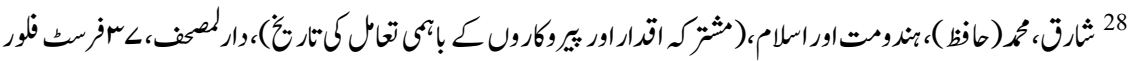

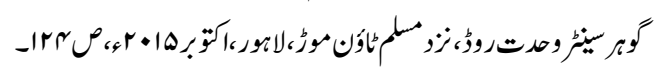

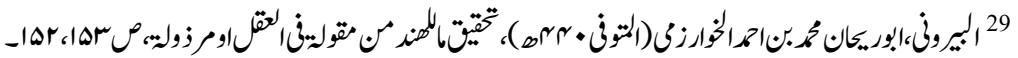

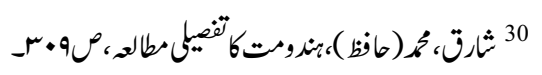

$$
\text { 31 } 31
$$

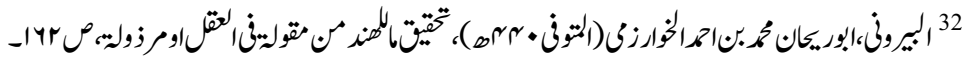

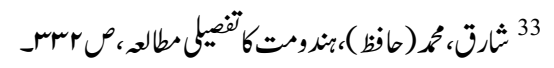

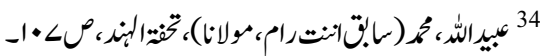

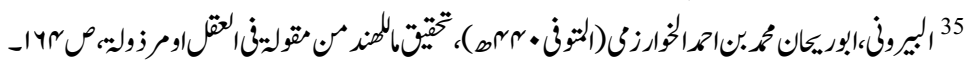

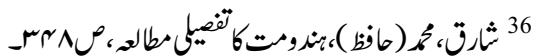

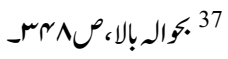

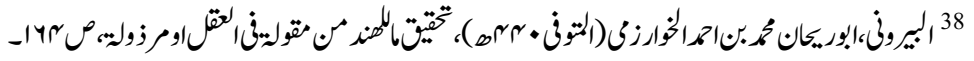

